\title{
Cyclosporin in the management of polymyositis and dermatomyositis
}

\author{
C J Lueck, P Trend, $M$ Swash
}

\begin{abstract}
Three patients with polymyositis refractory to conventional steroid and immunosuppressive treatment, but responsive to cyclosporin $A$, are described. In a fourth patient cyclosporin $A$ was used as a first line drug in combination with steroids in the treatment of lifethreatening dermatomyositis. Cyclosporin $A$ in the management of polymyositis/dermatomyositis requires formal assessment of its costs and benefits compared with conventional treatments.
\end{abstract}

Polymyositis is an inflammatory disease of muscle of uncertain aetiology, characterised by muscle weakness and often accompanied by pain, tenderness and wasting. Treatment with corticosteroids and, sometimes, with immunosuppressive agents (for example, azathioprine, methotrexate, or cyclophosphamide) is moderately effective in many cases. ${ }^{1}$ Not all patients, however, respond well to this treatment. Various other therapies have therefore been tried, including anti-lymphocyte globulin, plasma exchange, and total body irradiation, but with variable success. ${ }^{12}$

Cyclosporin $\mathrm{A}$ is an immunosuppressive agent which is well-established in the transplantation of organs including kidney, liver and bone marrow. It acts by inhibiting the production of interleukin 2 , thereby blocking both the development of cytotoxic lymphocytes, and the proliferation of $\mathrm{T}$ helper cells. ${ }^{3} \mathrm{~T}$ cell-mediated muscle cell damage is thought to be important in the pathogenesis of polymyositis, ${ }^{4}$ and it is therefore likely that cyclosporin A would be effective in the management of this condition. It has been used successfully in the treatment of childhood-type dermatomyositis ${ }^{56}$ and there is a report of its use in polymyositis. ${ }^{7}$ We have used cyclosporin A in polymyositis refractory to other immunosuppressive drugs, and report our experience in four patients.

\section{Patients}

Clinical details are summarised in the accompanying table.

Case 1 This 48 year old woman was admitted with a five year history of polymyositis, which had presented with muscle pain, weakness and weight loss. Initially treated with high-dose prednisolone and azathioprine, she had been unble to reduce the dose of steroid without a return of her weakness and had gained $9 \mathrm{~kg}$ in weight. More recently she had developed increasing weakness while on therapy, and on examination she had proximal muscle weakness (MRC grade 4). The creatine kinase (CK) level was $1109 \mathrm{iu} / 1$, and the EMG showed changes consistent with active polymyositis. A muscle biopsy showed muscle fibre hypertrophy and splitting, with scattered, necrotic and regenerating fibres, but no inflammatory infiltrate. There was early fibre type grouping. There were no features suggestive of steroid myopathy. Azathioprine was stopped, and she was started on cyclosporin $100 \mathrm{mg}$ twice a day $(2.5 \mathrm{mg} / \mathrm{kg} /$ day). Prednisolone was continued at $40 \mathrm{mg} /$ day. On this regime she steadily improved and one year later had reduced her steroid dose to $5 \mathrm{mg}$ on alternate days. Renal function remained normal, and there was no excess growth of body hair. Her body weight returned to normal.

Case 2 This 29 year old Pakistani woman was admitted with a one year history of pain, stiffness and weakness in her arms and legs. A diagnosis of polymyositis had been made elsewhere eight months previously on the basis of abnormal EMG and muscle biopsy. She had been treated with azathioprine and prednisolone. On reduction of her steroid dose, she had a relapse eight months later. No improvement in her weakness followed reintroduction of the prednisolone at a dose of $60 \mathrm{mg} /$ day. At this time there was proximal muscle weakness (MRC grade 3-4) and her CK was $2000 \mathrm{iu} / \mathrm{l}$. EMG showed typical low amplitude polyphasic motor units, and muscle biopsy showed scarring, fat replacement and

Table Patient details

\begin{tabular}{|c|c|c|c|c|c|c|c|}
\hline $\begin{array}{l}\text { Patient } \\
\text { number }\end{array}$ & Age/sex & $C K(i u / l)$ & $E M G$ & $\begin{array}{l}\text { Muscle } \\
\text { biopsy }\end{array}$ & $\begin{array}{l}\text { Previous } \\
\text { therapy }\end{array}$ & $\begin{array}{l}\text { Initial steroid } \\
\text { dose (mg/day) }\end{array}$ & $\begin{array}{l}\text { Final steroid } \\
\text { dose (mg/day) }\end{array}$ \\
\hline $\begin{array}{l}1 \\
2 \\
3 \\
4\end{array}$ & $\begin{array}{l}48 \mathrm{~F} \\
29 \mathrm{~F} \\
26 \mathrm{~F} \\
47 \mathrm{~F}\end{array}$ & $\begin{array}{l}1109 \\
2000 \\
6000 \\
1261\end{array}$ & $\begin{array}{l}+ \\
+ \\
+ \\
+\end{array}$ & $\begin{array}{l}+ \\
+ \\
+ \\
+\end{array}$ & $\begin{array}{l}\text { PRED/AZA } \\
\text { PRED/AZA } \\
\text { PRED/AZA } \\
-\end{array}$ & $\begin{array}{r}40 \\
100 \\
80 \\
100\end{array}$ & $\begin{array}{l}2 \cdot 5 \\
15 \\
10\end{array}$ \\
\hline
\end{tabular}


active muscle fibre necrosis and regeneration. She was started on cyclosporin $200 \mathrm{mg}$ twice a day ( $6 \mathrm{mg} / \mathrm{kg} /$ day) and the dose of prednisolone was increased to $200 \mathrm{mg} /$ day. Three months later muscle strength had improved considerably, the CK had fallen to $339 \mathrm{iu} / 1$, and she had been able to reduce her steroid dose to $30 \mathrm{mg}$ on alternate days. The dose of cyclosporin was reduced to $100 \mathrm{mg}$ twice a day to keep plasma levels in the therapeutic range. There was some excess growth of facial hair, but renal function was normal.

Case 3 This 26 year old Bangladeshi woman was admitted with an eight month history of progressive muscle weakness. On admission, her proximal musculature was profoundly weak (MRC grading 2-3), and there was muscle tenderness. Her CK level was greater than $6000 \mathrm{iu} / 1$, EMG revealed polyphasic motor unit potentials with fibrillations, and the muscle biopsy showed necrotic and regenerating fibres with interstitial inflammatory changes, together with rare dark-rimmed intracellular vacuoles. She was treated with prednisolone $(80 \mathrm{mg} /$ day $)$ and azathioprine, but continued to deteriorate in hospital, becoming unable to sit or stand unaided. Six plasma exchanges were performed without improvement. Three months after admission cyclosporin was substituted for azathioprine at a dose of $100 \mathrm{mg}$ twice a day $(3.5 \mathrm{mg} / \mathrm{kg} /$ day), and her deterioration ceased. She then gradually improved to the point that three months after the introduction of cyclosporin she was discharged walking slowly but unaided. In the six months after discharge, improvement continued so that she could again manage stairs and perform housework. Her steroid dose was discontinued, but cyclosporin was continued. Renal function was not impaired, but she has been troubled by excess growth of body and facial hair.

Case 4 This 47 year old Peruvian woman was admitted with a ten day history of profound weakness of her arms and legs (MRC grade 23) as well as severe difficulty in swallowing. For three months before admission she had noted oedema and a heliotrope rash affecting her face, hands, and feet. Dermatomyositis was diagnosed, supported by a creatine kinase level of $1261 \mathrm{iu} / 1$, and electromyographic findings of transient fibrillation and positive sharp waves, with florid polyphasic motor unit action potentials. Skin biopsy showed basal layer damage, pigmentary incontinence and a mild chronic inflammatory infiltrate of the upper dermis. Muscle biopsy showed abnormal variability in fibre size, perifascicular atrophy, scattered necrotic/regenerating small fibres and a small cell infiltrate in the endomysium. When transferred she was febrile, in respiratory distress, and unable to cough. Tracheostomy was performed, and nasogastric feeding instituted. Treatment was started with prednisolone $100 \mathrm{mg} /$ day, and cyclosporin $400 \mathrm{mg}$ twice a day $(6 \mathrm{mg} / \mathrm{kg} /$ day $)$. There was steady im- provement that started about 10 days later. Four months later her tracheostomy was closed and she was discharged home able to walk and feed herself. Improvement continued and the steroid dose was gradually reduced to $20 \mathrm{mg}$ on alternate days. Cyclosporin therapy was continued at a lower dose (150 $\mathrm{mg}$ twice a day).

\section{Discussion}

Cyclosporin appears to be an effective agent in the treatment of polymyositis and dermatomyositis. Our experience in managing patients who have failed to respond to, or have relapsed on, treatment with steroids and more conventional immunosuppressive drugs suggests that cyclosporin is at least as effective as, if not better than, other treatments. Management with cyclosporin initially requires monitoring of plasma levels and of renal function. ${ }^{8}$ However, once the optimum dose has been determined, management is similar to that of other immunosuppressive drugs. In our experience, the only troublesome side-effect has been hirsutism, affecting principally cases 2 and 3. We believe cyclosporin should be considered as a first line agent in the management of polymyositis and dermatomyositis, as in case 4 , since the unwanted effects of high-dose steroids are a considerable hazard in the management of this condition. Our experience does not address the role of cyclosporin as sole treatment in acute polymyositis, but the improvement in cases 1 and 2 who were refractory to high dose steroids clearly suggests that it is effective. In case 3 there were histological features suggestive of inclusion body myositis, a disorder generally regarded as refractory to conventional immunosuppresive treatment. ${ }^{9}$ The improvement that occurred in this case suggests a possible role for cyclosporin $A$ in this condition. The best option of the treatments available for steroid-unresponsive or resistant polymyositis is not known, but the role of cyclosporin in this situation appears promising. The role of cyclosporin in inflammatory muscle disease should now be assessed in a comparative trial against other treatments.

1 Ansell BM. Management of Polymyositis and Dermatomyositis. Clin Rheum Dis 1984;10:205-13

2 Swash M, Schwartz MS. Neuromuscular Diseases: a practical approch to diagnosis and management, 2nd ed. London: Springer-Verlag, 1988:269.

3 Bunjes D. Studies on the mechanism of action of cyclosporin $A$ in murine and human $T$-cell response in vitro. In: White DJG, ed. Cyclosporin A. Amsterdam: Elsevier Biomedical Press, 1982:261-80.

4 Dawkins RL, Mastaglia FL. Cell-Mediated Cytotoxicity to Muscle in Polymyositis. Effect of Immunosuppression. New Eng J Med 1973;288:434-8.

5 Zabel P, Leimenstoll G, Gross WL. Cyclosporin for Acute Dermatomyositis. Lancet 1984;i:343.

6 Ejstrup L. Severe Dermatomyositis Treated with Cyclosporin A. Ann Rheum Dis 1986;45:612-3.

7 Bendtzen K, Tvede N, Andersen V, Bendixen G. Cyclosporin for Polymyositis. Lancet 1984;i:792-3.

8 The Multiple Sclerosis Study Group. Efficacy and Toxicity of Cyclosporine in Chronic Progressive Multiple Sclerosis: a Randomised, Double-Blinded, PlaceboControlled Clinical Trial. Ann Neurol 1990;27:591-605.

9 Carpenter S, Karpati G, Heller I, Eisen A. Inclusion Body Myositis: A Distinct Variety of Idiopathic Inflammatory Myopathy. Neurology 1978;28:8-17. 